\title{
IMPLEMENTASI PROGRAM TAḤFIẒ AL-QUR' AN SEMESTER GENAP TAHUN AJARAN 2017/2018 DI KELAS 1 C MIN 1 YOGYAKARTA
}

\author{
Khodijah Noor Rahmawati'), Nur Hidayat ${ }^{2}$ \\ UIN Sunan Kalijaga Yogyakarta \\ Email:khodijahnorrahma@gmail.com ${ }^{1)}$,bos_hidayat@yahoo.com ${ }^{2}$ \\ Naskah diterima : 27 Februari 2019, direvisi : 6 April 2019, disetujui : 18 April 2019
}

\begin{abstract}
Seeing the reality of this modern age, many influences of technology and play facilities are increasingly diverse, so it is not easy to raise awareness for Muslims, especially children to memorize the Qur'an, because it would be easier if memorizing the Koran began early age, so that the child will more quickly absorb the memory to achieve the expected memorization, then a place is needed to motivate and memorize the Qur'an. One of the schools that teaches the tahfiz al-Qur'an program is class 1 C MIN 1 Yogyakarta. The objectives of this study are: (1) To find out the implementation of tahfiz al-Qur'an learning program in the semester of 2017/2018 academic year in class 1 C MIN 1 Yogyakarta, (2) To find out the methods used in tahfiz al-Qur'an learning even semester 2017/2018 academic year in class 1 C MIN 1 Yogyakarta, (3) To find out the supporting and inbibiting factors of ta'fi learning al-Qur'an the even semester of the academic year 2017/2018 in class 1 C MIN 1 Yogyakarta. This study uses a qualitative approach. The research subjects were class teachers and first grade students of C MIN 1 Yogyakarta, the object of this research was the implementation of the Qur'anic ta'fi program in class $1 \mathrm{C}$. data collection in this study through observation, interviews and documentation studies, and based on the data obtained the author of the analysis by focusing on things that are the subject of discussion, triangulation of data and drawing conclusions. Based on the results of the research in the field the authors obtained findings including: (1) the background of the program tahfih al-Qur'an in class 1 C MIN 1 Yogyakarta, namely the demands of the times and needs of class, parents, and students; (2) the aim of the tahfiz al-Qur'an program is to print the memorizing generation of the Qur'an early; (3) tah fih program is required for class 1 C with the target of memorizing juz 30 in odd semester and selected letters in even semester; (4) material covering juz 30 and selected letters chosen by the class teacher; (5) the scoring system in the form of daily deposits and financial examinations; (6) tahfi pembelajaran learning process includes opening, muraja'ah, adding memorization, deposit and closing; (7) the methods used are Bi al-Nażar, Takerir, Jama ', Sima'i and Talaqqï; (8) supporting factors include student motivation and interest, use of mental rbythms, teacher attention, conducive time and appreciation for students who have passed memorization; (9) inbibiting factors, namely the ability of different students, less able to manage time, lack of parental attention and almost the same.
\end{abstract}

Keywords: taḥfiz program, taḥiz al-Qur'an

Pengutipan: Hani Handayani. (2019). Analisis Kemampuan Representasi Siswa Pada Materi Volume Kubus dan Balok di SDN Manangga Kabupaten Sumedang. JMIE: Journal of Madrasah Ibtidaiyah Education,3(1), 2019, 62-71. jmie.v3i1.98.

Permalink/DOI: http://dx.doi.org/ 10.32934/jmie.v3i1.98 


\section{PENDAHULUAN}

Pendidikan merupakan usaha sadar dan terencana untuk mewujudkan suasana belajar dan pembelajaran agar peserta didik secara aktif mengembangkan potensi dirinya untuk memiliki kekuatan spiritual keagamaan, pengendalian diri, kepribadian, kecerdasan, akhlak mulia serta keterampilan yang diperlukan dirinya dan masyarakat, pendidikan meliputi pengajaran keahlian khusus, juga sesuatu yang tidak dapat dilihat tetapi lebih mendalam yaitu pemberian pengetahuan, pertimbangan dan kebijaksanaan. Dalam arti luas pendidikan menyangkut seluruh pengalaman, sedangkan dalam arti sempit pendidikan adalah yang dilakukan di sekolah (Ahmad Tafsir, 2008: 5).

Pendidikan Islam merupakan usaha untuk memperkuat iman dan ketakwaan terhadap Tuhan Yang Maha Esa sesuai dengan agama yang dianut oleh peserta didik yang bersangkutan dengan memperhatikan tuntutan untuk menghormati agama lain dalam hubungan kerukunan antar umat beragama dalam masyarakat untuk mewujudkan persatuan nasional. Ilmu pendidikan Islam merupakan ilmu pendidikan yang berdasarkanIslam, yang berisi ajaran-ajaran tentang kehidupan manusia, dan ajaran itu dirumuskan berdasarkan dan bersumber pada al-Qur'an, Hadis, dan akal. Dalam pendidikan agama Islam, al-Qur'an adalah hal pokok yang harus dipelajari dan dipahami oleh setiap muslim. Karena al-Qur'an merupakan landasan dan pedoman hidup umat muslim dalam menjalani kehidupan. Semua aspek kehidupan ini tercakup didalam al-Qur'an. Tujuan pendidikan Islam adalah menjaga dan mengoptimalkan fitrah (potensi) manusia agar berkembang menjadi manusia sempurna yang menjalankan tugas ubudiyahnya kepada Allah. Menurut al-Qur'an, manusia diciptakan oleh Allah untuk beribadah kepada-Nya.Kalam Allah yaitu al-Qur'an adalah cahaya yang gemerlap di hati orang yang beriman, firman Allah SWT dalam surat al-Ankabut (29) ayat 49:

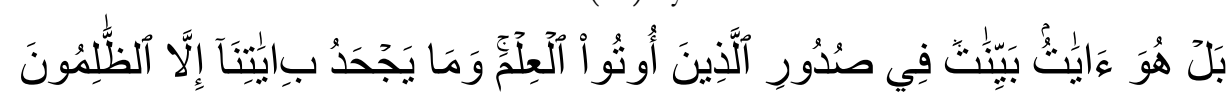

Artinya: Sebenarnya, al-Qur'an itu adalah ayat-ayat yang nyata di dalam dada orang-orang yang diberi ilmu. dan tidak ada yang mengingkari ayat-ayat Kami kecuali orang-orang yang zalim (Depag RI, 2008: 402).

Agama Islam mengandung jalan hidup manusia yang paling sempurna dan memuat ajaran yang menuntun umat Islam kepada kebahagiaan dan kesejahteraan, dapat diketahui dasar-dasar dan perundang-undangannya melalui al-Qur'an. al-Qur'an adalah sumber utama Islam. Hukumhukum Islam mengandung serangkaian pengetahuan tentang akidah, pokok-pokok akhlak dan perbuatan dapat dijumpai sumbernya dalam ayat-ayat al-Qur'an (Thabathabaí, 1987: 21).

Al-Qur'an adalah kalam Allah SW'T berupa mukjizat yang diturunkan kepada nabi Muhammad SAW secara berangsur-angsur sebagai petunjuk bagi umat manusia hingga akhir zaman, ditulis dalam mushaf diawali dengan surat al-Fatihah dan diakhiri dengan surat an-Nas, diriwayatkan secara mutawatir dan membacanya termasuk ibadah. Seseorang yang selalu 
berinteraksi dengan al-Qur'an yakni dengan mengimaninya, membacanya, mendengarkan, menghafalkan, memahami makna, ataupun mengamalkannya dengan menjadikannya sebagai pedoman dalam kehidupannya, maka ia akan mendapatkan keutamaan dan kemuliaan disisi Allah baik di dunia maupun di akhirat (Nada, 2015).

al-Qur'an adalah kitab suci yang sempurna dan berfungsi sebagai pelajaran bagi manusia, pedoman hidup bagi setiap muslim, petunjuk bagi orang-orang yang bertaqwa. Mengingat demikian pentingnya al-Qur'an dalam memberikan dan mengarahkan kehidupan manusia, maka belajar membaca, memahami dan menghayati al-Qur'an kemudian diamalkan dalam kehidupan sehari-hari merupakan kewajiban bagi seluruh umat Islam. Supaya bisa memahami, mempelajari dan mengamalkan al-Qur'an dalam kehidupan sehari-hari langkah utama yang harus dilakukan adalah dengan mampu membaca al-Qur'an. Hal ini sesuai dengan ayat pertama yang turun, yaitu ayat 1-5 dari surat al-'Alaq. Wahyu pertama yang diturunkan adalah iqra' bismi rabbika yang artinya "bacalah dengan menyebut nama Tuhanmu". Makna dari kata iqra' itu sendiri bukan hanya dalam segi membaca al-Qur'an, melainkan juga dalam aspek pemahaman dan penerapan atau pengaplikasian makna yang terdapat dalam al-Qur'an dalam kehidupan sehari-hari. Untuk bisa membaca al-Qur'an dengan benar sesuai dengan syariat Islam yang harus dilakukan proses belajar. Dalam hal ini. 'bacaan yang fundamental adalah al-Qur'an dialah yang pertama-tama harus dibaca, maka dari itu harus ada upaya untuk membaca al-Qur'an (Mutia, 2017).

Tradisi menghafal al-Qur'an merupakan salah satu upaya nyata umat Islam untuk menjaga kemurnian isi dari al-Qur'an. Pada masa permulaan Islam, setiap kali Nabi Muhammad SAW menerima wahyu, beliau menyampaikan kepada para sahabat dan memerintahkan mereka untuk menghafalkannya. Oleh karena itu maka tradisi tersebut masih berlaku hingga sekarang dan dianggap sebagai amal ibadah demi menjaga keotentikan ayat-ayat al-Qur'an. Tradisi menghafal dan menyalin al-Qur'an telah lama dilakukan di Indonesia. Berawal dari usaha menghafal perorangan melalui guru tertentu maupun lembaga non tạfiz, hingga kini sudah banyak terbentuk pondok pesantren maupun sekolah-sekolah khusus tạ fiz al-Qur’an.

Dalam dunia pendidikan baik yang formal maupun non-formal, keberhasilan dan ketercapaian merupakan hal yang sangat penting yang harus diperhatikan. Pendidikan formal maupun non-formal, dewasa ini semakin berbenah diri dalam meningkatkan mutu pendidikannya agar ketercapaian dan keberhasilan semakin mudah untuk dicapai. Salah satu cara yang dapat dilakukan oleh sekolah dalam meningkatkan mutu pendidikan adalah dengan mengefektifkan proses pembelajaran, sehingga hasil yang diperoleh akan terus meningkat dari waktu kewaktu. Dengan meningkatnya hasil yang diperoleh dari proses pembelajaran yang dilakukan, menunjukkan bahwa keberhasilan dan ketercapaian sekolah dalam melahirkan insaninsan yang edukatif, pada akhirnya memberikan nilai plus terhadap meningkatnya mutu pendidikan di sekolah tersebut.

Materi pembelajaran al-Qur'an meliputi pengajian membaca al-Qur'an dengan tajwid, sifat dan makhrajnya. Selain itu juga terdapat kajian makna, terjemahan dan tafsirnya. Para pakar 
pendidikan sepakat bahwa al-Qur'an adalah materi pokok dalam pendidikan Islam yang harus diajarkan kepada anak didik (Majid Khon, 2012: 13). Orang tua dan guru agama Islam memiliki keharusan untuk memberi pengajaran tentang al-Qur'an kepada anak-anak. Semua itu dapat dimulai dengan mengajarkan cara membaca al-Qur'an yang baik dan benar serta membimbing anak-anak tersebut untuk menghafalkan ayat-ayat di dalam al-Qur'an. Usaha nyata untuk memelihara kemurnian al-Qur'an adalah dengan menghafalkannya, karena menghafalkan alQur'an merupakan suatu pekerjaan yang sangat mulia di hadapan manusia dan dihadapan Allah SWT. Tidak ada suatu kitab pun di dunia ini yang dihafal oleh puluhan ribu orang di dalam hati mereka, kecuali hanya al-Qur'an yang telah dimudahkan oleh Allah SWT. Untuk diingat dan dihafal Sebagaimana Firman Allah dalam Surat al-Qamar (54) ayat 17:

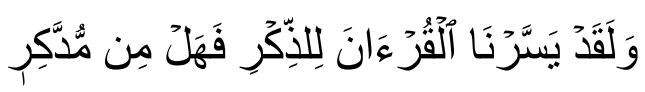

Artinya: dan Sesunggubnya telah Kami mudabkan al-Qur'an untuk pelajaran, Maka Adakah orang yang mengambil pelajaran?

Menurut Abdul Aziz Abdul Ra'uf Al Hafidzh menjelaskan, dalam proses menghafal alQur'an, hendaknya setiap orang memanfaatkan usia-usia yang berharga, sebagaimana yang dilakukan oleh orang sholeh terdahulu dalam mengajarkan al-Qur'an pada anak-anaknya, mereka melakukan sejak usia dini, sehingga banyak hafal al-Qur'an pada usia sebelum aqil baligh, Imam Syafi'i misalnya telah hafal al-Qur'an usia 10 tahun, begitupun Ibnu Sina, seorang alim dibidang kedokteran (Al Hafiz, 2004: 32).

Pada awal perkembangan anak adalah masa yang sangat penting, jika anak pada masanya sudah ditanami agama sejak dini maka besarnyapun akan menjadi anak yang berpikiran cerdas, daya hafal yang kuat dan dapat mengamalkan kandungan al-Qur'an. dengan itu akan terbentuk manusia yang berakhlakul karimah. Masalahnya sekarang bagaimana meningkatkan kualitas hafalan, yang masih dianggap oleh sebagian anak sebagai hafalan yang sulit. Hal ini merupakan tantangan bagi guru dalam menemukan pembelajaran yang tepat bagi anak. Oleh sebab itu, dalam proses tahfiz al-Qur'an diperlukan pembelajaran yang tepat dan cocok, dengan mempertimbangkan berbagai kemungkinan dalam proses pembelajaran tersebut.

Mengajarkan al-Qur'an hendaklah dimulai sejak dini, sebab masa anak-anak adalah masa awal perkembangan manusia sehingga nilai-nilai yang terkandung dalam al-Qur'an akan tertanam kuat pada dirinya dan akan menjadi tuntunan dan pedoman hidupnya. Selain itu menghafal al-Qur'an sejak dini akan lebih mudah daya serapnya, karena belum terbebani masalah kehidupan pada masa dewasa. Sedangkan menurut analisis Bloom, 50\% keterampilan membaca orang dewasa terbina antara usia 4-9 tahun (Suyadi, 2014: 33).

Melihat di zaman modern ini, banyaknya pengaruh teknologi dan berbagai fasilitas bermain yang semakin beragam tentu dapat berdampak positif dan juga negatif. Hal ini menyebabkan upaya untuk menumbuhkan kesadaran bagi umat Islam, khususnya anak-anak 
untuk dapat belajar menghafalkan al-Qur'an menjadi persoalan yang tidak mudah. Masyarakat muslim khususnya orang tua, ulama, guru dituntut untuk memiliki sikap peduli dan prihatin terhadap kondisi dan dunia anak-anak sebagai generasi penerus. Oleh karena itu, dibutuhkan suatu wadah atau tempat untuk menggerakkan dan memotivasi anak-anak dalam menghafal alQur'an. Karena untuk menjadikan muslim sejati, membutuhkan proses pembiasaan yang sangat intensif. Salah satu lembaga formal yang menjadi wadah tậfiz al-Qur'an adalah sekolah maupun madrasah.

Semangat umat Islam jika diperhatikan saat ini semakin meningkat dengan banyaknya lembaga tậfiz, pesantren tạ̣fiz, bahkan di lembaga-lembaga pendidikan formal seperti sekolah maupun madrasah. Salah satu lembaga formal yang memberikan wadah untuk menghafal alQur'an bagi anak-anak adalah Madrasah Ibtidaiyah Negeri (MIN)1 Yogyakarta. MIN 1 Yogyakarta adalah lembaga pendidikan sekolah yang bercirikan dan bernafaskan Islam. Dalam mencetak generasi yang unggul di bidang agama. MIN 1 Yogyakarta memiliki pembelajaran taḥfiz al-Qur'an dalam rangka meningkatkan kecintaan anak pada ajaran agama terutama alQur'an yaitu pembelajaran taḥfiz al-Qur'an. Di MIN 1 Yogyakarta terdapat kelas khusus untuk taḥfiz al-Qur'an yaitu Kelas 1 C, dimana bermula dari program tahfiz yang diikuti oleh seluruh siswa-siswi MIN 1 Yogyakarta. Ibu Sri Wahyuni, selaku Wali kelas 1 C mempunyai ide untuk mengaktifkan program khusus tahfiz untuk kelas $1 \mathrm{C}$ yang diampunya. Program tạ̣fiz di Kelas $1 \mathrm{C}$ ini sudah dilaksanakan selama lima tahun terakhir. Tujuan diadakannya program ini adalah untuk menjadikan siswa-siswi menjadi anak soleh, serta mencetak generasi Qur'ani sejak dini. Seperti slogan dikelas 1 C "anak pintar belum tentu soleh, tetapi anak soleh sudah pasti pintar". Atas dasar itulah, Ibu Sri Wahyuni, selaku Wali kelas $1 \mathrm{C}$ mengaktifkan program khusus taḥfiz al-Qur'an ini. Sehingga kelas $1 \mathrm{C}$ ini diharapkan bisa menjadi pionir bagi kelas-kelas lain. ${ }^{1}$

Di kelas 1C ini, penulis mengambil data pada semester genap tahun ajaran 2017/2018, pada saat ini beberapa siswa telah memasuki hafalan surat-surat pilihan yaitu surat al-Mulk. Pada semester ganjil siswa ditargetkan hafal juz 30, sehingga pada semester genap ini siswa memasuki surat-surat pilihan diantaranya surat al-Mulk, ar-Rahman, dan al-Wäqi'ah, namun hingga saat penulis melakukan pengamatan hafalan di lapangan, siswa baru memasuki hafalan surat al-Mulk. Untuk kedepannya siswa diharapkan mampu meningkatkan hafalannya dengan baik.

Melihat realita zaman sekarang, banyaknya pengaruh teknologi dan berbagai fasilitas bermain melalui media apapun dapat diakses oleh siswa-siswa tanpa pengawasan dari orang tua. Dengan berbagai media tersebut mereka dapat menggunakan hal yang positif maupun yang negatif. Mereka terkadang lebih memilih main game daripada belajar bahkan menghafal alQur'an. Untuk itu pendidik harus pandai mencari cara dan memotivasi siswa dalam proses pembelajaran yang bervariatif agar anak tidak merasa jenuh. Memang sulit menanamkan atau mengajarkan siswa-siswanya agar hafal al-Qur'an. maka dari itu penulis tertarik untuk meneliti

\footnotetext{
2018.

${ }^{1}$ Wawancara dengan Sri Wahyuni,Guru kelas $1 \mathrm{C}$, di ruang kelas $1 \mathrm{C}$, Tanggal 21 Februari 
bagaimana pelaksanaan pembelajaran tậiz al-Qur'an semester genap tahun ajaran 2017/2018 di kelas 1 C MIN 1 Yogyakarta. Dalam hal ini mencakup upaya guru dalam meningkatkan kemampuan dalam proses pembelajaran berlangsung.

\section{HASIL PENELITIAN DAN PEMBAHASAN}

\section{Pelaksanaan Pembelajaran Taḥfiz al-Quran di MIN 1 Yogyakarta}

Upaya pelestarian al-Qur'an melalui hafalan sebaiknya dilakukan mulai sejak dini. Melihat pada usia dini anak belum banyak mendapat pengaruh terhadap hal-hal negatif serta daya ingatnya masih kuat. Oleh karena itu, menyadari persoalan tersebut wali kelas $1 \mathrm{C}$ MIN 1 Yogyakarta memasukkan program taḥfiz al-Qur'an sebagai bagian dari pembelajaran di kelas 1 C MIN 1 Yogyakarta.

Berdasarkan hasil pengamatan penulis, proses pembelajaran taḥiz di kelas 1 C MIN 1 Yogyakarta berlangsung selama 30 menit pada hari Senin-Kamis dan hari Sabtu, sedangkan pada hari Jumat berlangsung selama 60 menit, karena bersamaan dengan setoran rutin. Pelaksanaan pembelajaran dimulai pukul 07.30 dan berakhir pukul 08.00. Khusus hari Jumat pembelajaran tahfiz dimulai pukul 07.30-08.30.2

Kekhasan program yang diselenggarakan oleh wali kelas 1 C MIN 1 Yogyakarta ini tidak banyak dilakukan oleh kelas-kelas lain pada umumnya. Biasanya kelas lain hanya melakukannya dipagi hari saja sebelum pembelajaran berlangsung. ${ }^{3}$ Dimana selain belajar kurikulum, juga harus mengimbanginnya dengan belajar al-Qur'an. Oleh karena itu, kelas 1 C MIN 1 Yogyakarta ini menjadi kelas unggulan yang setiap tahun ajaran baru banyak diminati, bahkan ada wali murid yang menitipkan nama anaknya untuk belajar di kelas $1 \mathrm{C}$ ini.

Wali kelas 1 C MIN 1 Yogyakarta melakukan program tersebut tentunya memiliki beberapa tujuan. Pertama, agar siswa hafal minimal juz 30 atau juz. 'Amma. Hal ini perlu disadari, bahwa kemampuan membaca al-Qur'an dikalangan masyarakat, khususnya bagi anak-anak merupakan bekal agar dapat membaca al-Qur'an secara fasih dan tartil. Kedua, program taḥfiz al-Qur'an di kelas 1 C MIN 1 Yogyakarta bertujuan untuk mendorong, membina dan membimbing siswa untuk menyukai, menghafalkan dan mengamalkan al-Qur'an dalam kehidupan sehari-hari. Ketiga, memberikan bekal kemampuan untuk mengikuti pendidikan dijenjang sekolah selanjutnya. Hal ini jelas, bahwa pelaksanaan program taḥfiz al-Qur'an sebagai bagian untuk membekali anak kemampuan hafalan al-Qur'an untuk jenjang pendidikan selanjutnya. ${ }^{4}$ Dengan demikian, pelaksanaan program tahfiz al-Qur’an yang dilaksanakan oleh wali kelas 1 C MIN 1

\footnotetext{
${ }^{2}$ Observasi Proses Pembelajaran Taḩiz al-Qur'an, di Ruang Kelas 1 C, tanggal 2 Maret 2018.
} 
Yogyakarta merupakan bentuk kesadaran untuk melestarikan al-Qur'an sejak dini, membekali siswa dengan jiwa Qur'ani, sehingga perilakunya sesuai dengan tuntunan al-Qur'an.

Adapun tujuan utama dari implementasi program tahfiz al-Qur'an ini adalah untuk mencetak generasi penghafal al- Qur'an sejak dini, serta meningkatkan mutu siswa dan sekolah, agar dapat unggul dibidang akademik maupun non akademik. Demi tercapainya tujuan tersebut, ibu Sri Wahyuni selaku wali murid kelas 1 C MIN 1 Yogyakarta telah merumuskan target-target operasionalnya sebagai berikut: Pertama, Peserta didik dapat membaca al-Qur'an dengan benar, sesuai kaidah ilmu tajwid. Kedua, Dapat menghafalkan al-Qur'an minimal 1 juz, yaitu juz 'Amma. Ketiga, Dapat menghafalkan surat-surat pilihan (surat Yäsìn, ar-Rahmān, al-Wäqi'ab). Keempat, Dapat menghafalkan al-Qur'an juz 30 pada semester pertama. Kelima, Dapat menghafalkan alQur'an surat-surat pilihan pada semester kedua.5

Berdasarkan hasil wawancara dan observasi yang telah penulis lakukan, dapat diketahui bahwa sistem evaluasi atau penilaian pada pembelajaran tahfiz al-Qur'an di kelas 1 C MIN 1 Yogyakarta dilakukan melalui setoran hafalan untuk mengetahui tingkat hafalan siswa. aspek penilaian hafalan harian meliputi makhraj, kelancaran, tajwid dan lagunya. Penilaian yang diberikan menggunakan standar penilaian yang telah disepakati, yaitu maksimal 97 dan minimalnya 77, serta nilai KKM 80. Siswa yang mendapatkan nilai 80 atau lebih maka akan diberikan catatan $\mathrm{L}$ yaitu lanjut, dan bagi siswa yang mendapatkan nilai dibawah 80, maka akan diberikan catatan U yang artinya ulang. Siswa tersebut diwajibkan melancarkan hafalannya terlebih dahulu kemudian menyetorkan hafalannya kembali hingga mencapai nilai standar. Dalam hal ini, nilai setoran harian para siswa dalam satu semester akan diakumulasi, kemudian dirata-rata dan dijadikan nilai rapor siswa dalam bentuk huruf dan deskripsi.

Adapun kriteria dan standar penilaian taḥiz secara keseluruhan adalah sebagai berikut:

Tabel 1. Kriteria dan Standar Penilaian Taḥfiz al-Qur'an Semester Genap Tahun Ajaran 2017/2018 di Kelas 1 C MIN 1 Yogyakarta ${ }^{6}$

\begin{tabular}{ccl}
\hline Nilai angka & Nilai huruf & \multicolumn{1}{c}{ Nilai deskripsi } \\
\hline $95-97$ & A & $\begin{array}{l}\text { Hafalan sudah lancar, tajwid dan makhrajnya } \\
\text { sudah bagus. Sopan dan tekun dalam menghafal. } \\
\text { Hafalan sudah lancar, tajwid dan makhrajnya }\end{array}$ \\
$90-94$ & A- & $\begin{array}{l}\text { sudah cukup bagus. Sopan dan tekun dalam } \\
\text { menghafal. }\end{array}$ \\
\hline
\end{tabular}

\footnotetext{
${ }^{5}$ Wawancara dengan Sri Wahyuni, Guru Kelas 1C, di Ruang Kelas 1 C, Tanggal 2 Maret 2018.

${ }^{6}$ Wawancara dengan Sri Wahyuni, Guru Kelas 1C, di Ruang Kelas 1 C, Tanggal 2 Maret 2018.
} 


\begin{tabular}{ccl}
\hline Nilai angka & Nilai huruf & \multicolumn{1}{c}{ Nilai deskripsi } \\
\hline $85-89$ & B & $\begin{array}{l}\text { Hafalan sudah cukup lancar, tajwid dan } \\
\text { makhrajnya sudah cukup bagus. Sopan dan tekun } \\
\text { dalam menghafal, namun masih perlu diperbaiki. } \\
\end{array}$ \\
& Bafalan sudah cukup lancar, tajwid dan \\
$80-84$ & $\begin{array}{l}\text { makhrajnya masih perlu diperhatikan. Sopan dan } \\
\text { masih perlu bimbingan dalam menghafal. }\end{array}$ \\
& &
\end{tabular}

Evaluasi pembelajaran taḥfiz khusus untuk siswa yang sudah menyelesaikan hafalan dari surat an-Nas Sampai an-Nabā maka diadakan ujian tahfiz. Yaitu berupa sima'an yang dilaksanakan pada hari Jumat pagi. Ujian tahfiz dilaksanakan dengan ketentuan tertentu, yaitu sima'an. Dilaksanakan secara bergantian, beberapa siswa maju kedepan kelas. Siswa yang berhasil menyelesaikan ujian taḥfí dan memenuhi ketentuan tersebut maka akan dinyatakan lulus ujian, dan berhak melanjutkan hafalannya ke surat-surat pilihan. Surat-surat pilihan tersebut meliputi: al-Mulk, al-Wäqi'ah, dan ar-Rahnmān. Pada semester genap ini ibu Sri Wahyuni menargetkan lima surat yang dihafalkan, yaitu: surat an-Naba', an-Näri'àt, 'abasa, at- Taqwìr, dan Surat al-Mulk.

Berdasarkan hasil ujian taḥiz yang diberikan kepada tiga puluh siswa, menunjukkan bahwa siswa yang dinyatakan lulus berjumlah sembilan belas orang, dan sebelas orang belum lulus. Hal ini menunjukkan bahwa pelaksanaan program kelas tạ̣fị al-Qur’an di kelas $1 \mathrm{C}$ MIN 1 Yogyakarta semester genap tahun ajaran 2017/2018 dinyatakan efektif karena target yang dicapai melebihi separo siswa yang lulus.

\section{Metode Pembelajaran Taḥfiz al-Qur’an Semester Genap TA 2017/2018 di MIN 1 Yogyakarta}

Metode merupakan cara penting untuk mencapai suatu keberhasilan. Oleh karena itu pemilihan metode yang tepat sesuai dengan situasi dan kondisi siswa harus diperhatikan. Penggunaan metode yang tepat dalam proses menghafal al-Qur'an memudahkan siswa dalam menghafal al-Qur'an. Setiap siswa memiliki cara tersendiri dalam menghafal, bahkan ada beberapa siswa yang memadukan beberapa metode, sehingga siswa mudah mengingat apa yang dihafalnya. Dalam hal ini wali kelas membebaskan metode yang digunakan oleh siswa. Akan tetapi wali kelas menyamakan irama menggunakan murottal Muhammad Thoha Al-Junaid versi anak-anak, agar saat membaca bersama-sama dikelas memiliki nada yang sama.

Adapun metode-metode yang digunakan guru di kelas 1 C MIN Yogyakarta berdasarkan hasil wawancara dan observasi antara lain, pertama, Metode Bì al-Nażar atau melihat yaitu membaca cermat ayat al-Qur'an yang akan dihafalkan. Kedua, Metode Takrì, yaitu guru 
membacakan ayat-ayat yang akan dihafal kemudian siswa mendengarkan, kemudian menirukan bersama-sama. Ketiga, Metode Jama', yaitu Siswa membaca bersama-sama hafalan yang telah di hafal pada pertemuan sebelumnya maupun yang baru dihafalkan dengan dipimpin oleh beberapa siswa yang sudah hafal ataupun yang piket pada hari itu. Keempat, Metode Sima’i, Pada metode ini ibu Yuni men-share di grub whats App wali siswa, murottal Muhammad Thoha Al-Junaid untuk menyamakan irama saat membaca surat-surat yang ditentukan. Kelima, Metode Talaqqi atau setor hafalan, metode setor selain sebagai metode sekaligus juga untuk menilai seberapa jauh hafalan siswa.

\section{Faktor Pendukung dan Penghambat}

Menghafal al-Qur'an merupakan suatu proses panjang, sehingga dalam pelaksanaannya tentu dipengaruhi oleh beberapa faktor. Terdapat dua faktor yang mempengaruhi implementasi program tahfiz al-Qur'an bagi siswa kelas 1C MIN 1 Yogyakarta. Yaitu faktor pendukung dan penghambat.

Faktor pendukung pembelajaran tahfiz al-Qur'an diantaranya: pertama, usia yang ideal. Kedua, Manajemen waktu. Ketiga, tempat menghafal. Sedangkan untuk faktor penghambatnya antara lain: pertama, tidak menguasai makhorijul ḥuruf dan tajwid. Kedua, tidak sabar. Ketiga, Tidak sungguh-sungguh. Keempat, Kurang dalam berdoa.

\section{KESIMPULAN}

Setelah mencermati paparan diatas, maka dapat disimpulkan antara lain: Pertama, Implementasi program tahfiz al-Qur'an di kelas 1C MIN 1 Yogyakarta ini berjalan dengan baik, namun tetap perlu adanya peningkatan agar semua tujuan yang diharapkan dapat tercapai dengan optimal. Pelaksanaan program kelas tahfiz al-Qur'an di kelas 1C MIN 1 Yogyakarta dilaksanakan pada hari senin sampai sabtu, setiap pagi hari sebelum pembelajaran dimulai. Muroja'ah dilakukan secara rutin setiap pagi hari selama 30 menit, dilakukan sebelum pembelajaran dimulai. Proses pembelajaran meliputi pembukaan, muroja'ah, menambah hafalan, setoran hafalan dan penutup. Kedua, Beberapa metode menghafal yang digunakan di kelas 1 C MIN 1 Yogyakarta yaitu: a) Metode $B \bar{\imath}$ al-Nażar yaitu membaca dengan cermat ayat-ayat al-Qur'an yang akan dihafalkan dengan melihat mushaf secara berulang-ulang. b) Metode Takrir adalah mengulang hafalan atau menyimakan hafalan yang sudah dihafalkan kepada ustad/guru. c) Metode Jama' membaca bersama-sama hafalan yang telah di hafal pada pertemuan sebelumnya maupun yang baru dihafalkan dengan dipimpin oleh beberapa siswa. d) Metode Șima’i yaitu mendengarkan suatu bacaan untuk dihafalkan. e) Metode Talaqqi yaitu menyetorkan hafalan yang telah dihafal kepada guru/ustad. Ketiga, Adapun faktor pendukung dalam pembelajaran taḥfiz al-Qur'an di kelas 1C MIN 1 Yogyakarta adalah: a) Usia yang ideal. b) Manajemen waktu. c) Tempat menghafal. 
Sedangkan untuk faktor penghambatnya sebagai berikut: a) Tidak menguasai makhorijul huruf dan tajwid. b) tidak sabar. c) Tidak sungguh-sungguh. d) Kurang dalam berdoa.

\section{DAFTAR PUSTAKA}

Al Hafizh, Abdul Ra’uf, Abdul Aziz, Kiat Sukses Menjadi Hafiæh Quran Da’iyah, Bandung: PT Syaamil Cipta Media, 2004.

Astiti, Nada Angger, Tahfidz Alquran Mempengaruhi Daya Ingat Anak di TK Islam Mardisiwi Pajang Laweyan SurakartaTahun ajaran 2014/2015,Tesis, Pendidikan Guru Pendidikan Anak Usia Dini, Universitas Muhammadiyah Surakarta, 2015.

Departemen Agama RI, Al-Hikmah; Alquran dan Terjemahnya,Bandung: CV Penerbit Diponegoro, 2008.

Khon, Abdul Majid, Hadis Tarbawi: Hadits-Hadits Pendidikan Cet. Ke-2, Jakarta: Kencana, 2012.

Observasi Proses Pembelajaran Tạ̣fiz al-Qur'an, di Ruang Kelas 1C, Tanggal 2 Maret 2018.

Suyadi, Teori Pembelajaran Anak Usia Dini, Jakarta: Kencana, 2012.

Tafsir, Ahmad, Metodelogi, Pengajaran Agama Islam, Bandung: Rosda Karya, 2008.

Thabathaba'i, M. H. Allamah, Mengungkap Rahasia Al-Qur'an, Penerjemah A. Malik Madani dan Hamim Ilyas, Bandung: Mizan, 1987.

Wahyuni, Sri, Guru Kelas 1C, di Ruang Kelas 1C MIN 1 Yogyakarta, 21 Februari 2018.

Wahyuni, Sri, Guru Kelas 1C, di Ruang Kelas 1C MIN 1 Yogyakarta, 2 Maret 2018.

Yomeina, Mutia, Hubungan Antara Persepsi Siswa terhadap Kegiatan Pembelajaran Tabsin dengan Kemampuan Siswa dalam Membaca Al Qur'an di lembaga Tarqi, Universitas Pendidikan Indonesia, repository. Upi.edu, 2017. 